\title{
Cognitive Linguistics and Metaphor Research: Past Successes, Skeptical Questions, Future Challenges
}

\author{
(A Lingüística Cognitiva e a Pesquisa Sobre Metáfora: Sucessos \\ Passados, Questionamentos Céticos, Futuros Desafios)
}

Raymond W. GiBBs, Jr.

(University of California, Santa Cruz - Dept. of Psychology)

\begin{abstract}
An important reason for the tremendous interest in metaphor over the past 20 years stems from cognitive linguistic research. Cognitive linguists embrace the idea that metaphor is not merely a part of language, but reflects a fundamental part of the way people think, reason, and imagine. A large number of empirical studies in cognitive linguistics have, in different ways, supported this claim. My aim in this paper is to describe the empirical foundations for cognitive linguistic work on metaphor, acknowledge various skeptical reactions to this work, and respond to some of these questions/criticisms. I also outline several challenges that cognitive linguists should try to address in future work on metaphor in language, thought, and culture.
\end{abstract}

KEY-WORDS: Cognitive Linguistics; Metaphor research; metaphor in language; metaphor in thought; metaphor in culture.

RESUMO: Uma importante razão para o grande interesse pela metáfora nos últimos 20 anos está na pesquisa realizada pela Lingüística Cognitiva. Os lingüistas cognitivos adotam a idéia de que a metáfora não é meramente uma parte da língua, mas reflete uma parte fundamental da nossa maneira de pensar, raciocinar e imaginar.Um grande número de estudos empíricos em Lingüística Cognitiva tem, de diferentes modos, oferecido suporte a essa idéia. Meu objetivo neste artigo é descrever os fundamentos empíricos do trabalho da Lingüística Cognitiva sobre a metáfora, apresentar vários questionamentos sobre esse trabalho, e responder algumas dessas questões/críticas. Eu também aponto vários desafios que a Lingüística Cognitiva deveria encarar em futuros trabalhos sobre a metáfora na língua, no pensamento e na cultura.

PALAVRAS-CHAVE: Lingüística Cognitiva; Pesquisa da metáfora; a metáfora na língua; a metáfora no pensamento; a metáfora na cultura.

D.E.L.T.A., 22:EsPECIAL, 2006 (1-20) 


\section{Introduction}

Metaphoric language has the dual function of reminding us of pervasive patterns of experience while alerting us to new conceptual and aesthetic possibilities. For example, when the poet A.R. Ammons writes that $A$ poem is a walk, he employs metaphor to tell us what a poem is (i.e., a poem is a leisurely, perhaps unpredictable, purposeful journey of the mind and imagination). Many readers familiar with poems may have never thought of poetry in quite this way, and their future experiences reading poems may be transformed as a result of understanding and appreciating Ammons' words. Other readers, however, may immediately recognize how they have already experienced poems as kinds of walks, and enjoyed Ammons' words precisely because they tap into a rich set of deeply ingrained beliefs. In both cases, metaphor serves to highlights thematic relations that define the world and our experiences of it.

A traditional belief among many scholars is that metaphorical meaning is created de novo, and does not reflect pre-existing aspects of how people ordinarily conceptualize ideas and events in terms of pervasive metaphorical schemes. But in the past 20 years, various linguists, philosophers, and psychologists have embraced the alternative possibility that metaphor is fundamental to language, thought, and experience (Gibbs, 1994; Gibbs \& Steen, 1999; Lakoff, 1987; Lakoff \& Johnson, 1980, 1999; Johnson, 1987; Sweetser, 1990). These scholars, working primarily under the new disciplinary umbrella titled "Cognitive Linguistics," have explored the idea that people speak metaphorically because they think, feel, and act metaphorically. This article critically evaluates this important revolution in metaphor studies. I briefly describe the intellectual foundations of cognitive linguistics, some of its empirical findings about metaphor in language and thought, and then consider various skeptical questions scholars have raised in response to this new work. My aim is to set the stage for future empirical, interdisciplinary studies in a way that properly acknowledges cognitive linguistics' significant contributions, but also suggest ways that cognitive linguistic research may be more rigorously defined and complemented by scholarship in related academic disciplines (e.g., psychology, applied linguistics, corpus linguistics). 


\section{The Rise of Cognitive Linguistics}

Cognitive linguistics began in the late 1970s in response to the dominant, generative paradigm in linguistics. Unlike the work in generative linguistics, defined by the Chomskyian revolution, cognitive linguists assume the analysis of the conceptual and experiential basis of linguistic categories and constructs is of primary importance: the formal structures of language are studied not as if they were autonomous, but as reflections of general conceptual organization, categorization principles, and processing mechanisms (Gibbs, 1994; Lakoff, 1990).

Cognitive linguistics has blossomed in part through the adherence to two different commitments (Lakoff, 1990). The "Generalization commitment" emphasizes that we seek general principles in our theoretical descriptions of linguistic phenomena. For example, in syntax there are generalizations about the distributions of grammatical morphemes, categories and constructions. In semantics there are generalizations about inferences, polysemy, semantic fields, conceptual structure, and so on. In pragmatics there are generalizations about communicative functions such as speech acts, implicatures, deixis, and language use in context. Cognitive linguistics takes as an empirical issue whether these domains are autonomous or related (e.g., is the distribution of grammatical morphemes influenced by semantics and pragmatics?).

The "Cognitive commitment" stresses the importance of incorporating a wide range of data from other disciplines in our theoretical description of language. This commitment compels cognitive linguists to recognize the empirical findings from related disciplines such as cognitive and developmental psychology, psycholinguistics, anthropology, neuroscience, and so on.

Cognitive linguists claim that metaphor is not merely a figure of speech, but is a specific mental, and neural mapping that influences a good deal of how people think, reason, and imagine in everyday life (Lakoff \& Johnson, 1999). Verbal metaphors do not exist as mere ornamental, communicative devices to talk about topics that are inherently difficult to describe in literal terms. Instead, verbal metaphors, including conventional expressions based on metaphor, reflect underlying conceptual mappings in which people metaphorically conceptualize of vague, abstract domains of knowledge (e.g., time, causation, spatial orientation, ideas, emotions, concepts of 
understanding) in terms of more specific, familiar, and concrete knowledge (e.g., embodied experiences). These source to target domain mappings tend to be asymmetrical (but see Fauconnier \& Turner, 2002) in that completely different inferences result when the direction of the mappings are reversed (e.g., TIME IS MONEY is quite different from the, perhaps, anomalous idea that MONEY IS TIME).

\section{Cognitive Linguistic Evidence}

There is a variety of evidence that supports the central claims of cognitive linguistics about metaphor. First, there is research from historical linguistics showing that metaphoric thought plays a role in the historical evolution of what words and expressions mean. Sweetser (1990) argued that many polysemous words in Indo-European languages acquired their nonphysical meanings over time via metaphorical extensions from earlier acquired, concrete, physical meanings. Thus, a metaphorical mapping between the ideas of visually seeing things to intellectually understanding things defines a pathway for semantic change. The presence of conceptual metaphors like UNDERSTANDING IS SEEING explains not only how words change their meanings historically (i.e., why the physical sense of "see" gets regularly extended via metaphor at a later point to have a nonphysical meaning), but also helps explain for contemporary speakers just why it is that polysemous words have the specific meanings they do (e.g., why it just makes sense to us to talk about understanding ideas using expressions like "I clearly see the point you're making in this essay"). With few exceptions, words in Indo-European languages meaning "see" regularly acquire the meaning "know" at widely scattered times and places.

A second major source of cognitive linguistic evidence on the ubiquity of metaphor in both language and thought comes from systematic analyses of contemporary, conventional linguistic expressions. This work claims that metaphoric thought motivates the linguistic meanings that have currency within linguistic communities, or may have some role in speakers'/hearers' presumed understanding of language. Consider the following fairly mundane utterances that are often used to talk about love and relationships in American English (Gibbs, 1994): 


\author{
"Look how far we've come." \\ "It's been a long, bumpy road." \\ "We're at a crossroads." \\ "We may have to go our separate ways." \\ "Our marriage is on the rocks." \\ "We're spinning our wheels."
}

All of these phrases are motivated by an enduring metaphor of thought, or conceptual metaphor, LOVE IS A JOURNEY, which involves understanding one domain of experience, love, in terms of a very different, and more concrete domain of experience, journeys. There is a tight mapping according to which entities in the domain of love (e.g., the lovers, their common goals, the love relationship, etc.) correspond systematically to entities in the domain of a journey (e.g., the traveler, the vehicle, destinations, etc.). Most theories of linguistic metaphor assume that these expressions are "literal" or perhaps merely "dead metaphors." The hypothesis that some concepts may be metaphorically structured, however, makes it possible to explain what until now has been seen as unrelated conventional expressions. A huge body of work demonstrates systematicity across many abstract target domains in many different languages (see the many papers in the journal Cognitive Linguistics). This work does not necessarily mean that all aspects of some abstract concept (e.g., love, personality, the mind) are metaphorical. At least part of these concepts are motivated by metaphorical schemes of thought.

There are now literally dozens of published studies illustrating the systematic presence of conceptual metaphors in people's use and understandings of conventional expressions in a variety of languages (Yu, 1999). Let me briefly describe just one recent set of findings that provides additional support for metaphor in human conceptual systems. This work is particularly noteworthy because it shows the presence of metaphorical thought in signed languages- American Sign Language (ASL).

A common conceptual metaphor with embodied roots in American English, and other languages, is COMMUNICATION IS SENDING AND RECEIVING OBJECTS. This conceptual metaphor underlies speakers' use and understanding of linguistic expressions such as "We tossed some ideas back and forth" and "His meaning went right over my head." In each case, 
ideas correspond to objects and the act of communicating corresponds to the sending and receiving of these objects. Recent work on American Sign Language (ASL) demonstrates that a similar conceptual metaphor underlies ideas about communication in ASL (Taub, 2001; Wilcox, 2001). ASL signers generally exploit signing space to schematically represent spatial relations, time, order, and aspects of conceptual structure. When signers describe spatial relations, there is a structural analogy between the form of a classifier construction and aspects of the described scene. Specifically, physical elements in ASL (the hands) map to physical elements within the scene (objects), movements of the hands map to the motion of referent objects, and locations in signing space map to physical locations within the scene. Through metaphorical mappings, signers can extend the use of classifier constructions and signing space to describe abstract concepts and relations.

However, the conceptual metaphors in ASL are different from those in spoken language, because they involve a double mapping (Taub, 2001). First, there is a metaphorical mapping from a concrete, embodied source domain to an abstract target domain (e.g., objects that can be grasped and passed to others are mapped onto ideas/thoughts/concepts). Second, there is an iconic mapping from the concrete domain to the linguistic domain (e.g., cylindrical objects map to cylindrical handshapes). For example, similar to English speakers, ASL signers use the communicating-as-sending metaphor. For both speakers and signers, the discourses of communicating ideas and throwing objects are linked whereby an idea corresponds to an object, and telling or explaining the idea corresponds to throwing the object to someone. But unlike spoken English, ASL has an additional iconic mapping between the concrete domain (objects) and the articulators (the hands). Consider the English statement "I didn't get through to him" in reference to a speaker trying to get a listener to understand some idea or belief. In ASL, the equivalent sign (paraphrased as THINK-BOUNCE) indicates a failure to communicate and consists of an iconic depiction of a projectile bouncing off a wall (the dominant handshape moves from the head and bounces off the non-dominant hand). Thus, ASL has two levels of human movement in the sign referring to failure to communicate. ASL exhibits double mappings in many abstract conceptual domains.

A related example of taking ideas out of one mind is illustrated by a signer who was attempting to write a book detailing all the jokes and folklore he has remembered from talking with deaf persons all over the 
world (Wilcox, 2001). The sign for "pool-ideas-into-book" began with the signer having both fists close to his forehead and then throwing them outward and downward toward his lap area, with fingers splayed out, into the place where a book might be written or read. Thus, the ideas are taken from the mind as a container and put into a different container or book.

The conceptual metaphor IDEAS ARE OBJECTS TO BE GRASPED is represented by a handshape with simultaneous iconic and metaphoric representations. Thus, a fully closed fist handshape is used in the sign to represent someone reaching out to grab objects as in "Ryan scooped up the jewels with one hand." This same classifier is employed in cases like "I will take grandmother with me," even if we don't literally grab people in taking them somewhere. Not surprisingly, the same sign can be used metaphorically as when signing "Hang onto that idea." This particular handshape maps the grasping of an object in a way that it cannot escape onto the intellectual process of permanently holding onto an idea in memory.

Linguistic analyses like these show how spoken and signed languages share many of the same systematic metaphorical mappings between embodied experiences/actions and more abstract conceptual domains. More generally, work on systematicity continues to flourish in cognitive linguistics, illustrating the ubiquity of metaphor in both language and thought.

A different source of evidence for the metaphorical motivation for linguistic expressions is seen in the ways conventional metaphors are elaborated upon in poetry and literature (Freeman, 1995; Lakoff \& Turner, 1989). Space limitations prevent me from discussing this evidence in detail. But one interesting analysis of Shakespeare's play "Macbeth" provides several nice examples of CONTAINER metaphors, which map the CONTAINER image-schema onto different target domains (Freeman, 1995). For example, the King of Norway, Sweno, is described as "that spring whence... Discomfort swells" (I.ii.27-28). Before her murder, Lady Macduff discovers herself contained "in this earthy world, where to do harm/Is often laudable, to do good sometime/ Accounted dangerous folly" (IV. ii.74-76). Duncan's murdered body is viewed as a container: "Yet who would have thought the old man to have had so much blood in him?" Finally, throughout the play, Lady Macbeth talks of herself and her husband as containers. She says of her husband 'Yet I do fear they nature/ It is too full o' th' milk of human kindness/ To catch the nearest way" (I.v.14-16). But she wishes for him to be empty of "human kindness" and to be fill with the liquid of her own 
spirits: "Hie thee hither/ That I may pour my spirits in thine ear/ And chastise with the valor of my tongue / All that impedes thee from the golden round" (I.v.23-26).

These few examples highlight just a small number of the many ways that our ideas about our containers are used to conceptualize many aspects of human traits. Each of them makes sense to us, both as ordinary readers and experienced critics, because of our own embodied understanding of containment experiences, which give rise to a whole host of conventional metaphors seen in everyday language (e.g., "I fell in love with him, but was dumped two months later" in which we think of love, as we do with many emotions, as a container that we are either in or out of). In this way, the study of poetic language also reveals the prominence of metaphor in creative imagination, and how these creative abilities are linked to enduring metaphorical schemes of thought.

There is one new development in cognitive linguistics that should significantly alter the way metaphors are studied and explained. This new advance aims to address two problems with conceptual metaphor theory. First, conceptual metaphors appear to differ in the way they are experientially grounded (Grady, 1997, 1999). Consider the well-known conceptual metaphor MORE IS UP (e.g., "Inflation is up this year"). It is easy to correlate having more of some objects or substance (i.e., quantity) with seeing the level of those objects or substance rise (i.e., verticality). But many conceptual metaphors do not suggest such straightforward experiential correlations. For instance, well-known conceptual metaphors THEORIES ARE BUILDINGS and LOVE IS A JOURNEY do not seem to have the same kind of correlation in experience as seen in MORE IS UP. Thus, actual travel has little to do with the progress of relationships, and theories are not closely tied to the buildings in which people generate, discuss, and dismantle these ideas.

A related problem with conceptual metaphor theory is that it does not explain why certain source-to-target domain mappings are not likely to occur (Grady, 1997, 1999). For instance, the conceptual metaphor THEORIES ARE BUILDINGS motivates many meaningful linguistic expressions such as "The theory needs to be buttressed" or "The foundation for your theory is shaky." But some aspects of buildings are clearly not mapped onto the domain of theories, which is one reason why in normal conversation it sounds odd to say "The theory has no windows." An interesting solution 
to these problems suggests that conceptual metaphors are not the most basic level at which metaphorical mappings exist in human thought and experience. Grady (1997) argued that strong correlations in everyday embodied experience leads to the creation of primary metaphors. These metaphorical correlations arise out of our embodied functioning in the world. In each case, the source domain of the metaphor comes from the body's sensorimotor system. A primary metaphor reflects a metaphorical mapping for which there is an independent and direct experiential basis and independent linguistic evidence. Presented below are several examples of these and associated linguistic expressions.

INTIMACY IS CLOSENESS (e.g., We have a close relationship)

IMPORTANT IS BIG (e.g., Tomorrow is a big day)

MORE IS UP (e.g., Prices are high)

HELP IS SUPPORT (e.g., Support your local charities

STATES ARE LOCATIONS (e.g., I'm close to being in a depression)

CHANGE IS MOTION (e.g., My car has gone from bad to worse)

PURPOSES ARE DESTINATIONS (e.g., He'll be successful, but isn't there yet) UNDERSTANDING IS GRASPING (e.g., I've never been able to grasp transfinite numbers)

These primary metaphors can be combined to form larger metaphorical wholes, called compound or complex metaphors. Consider the following three primitive metaphors: PERSISTING IS REMAINING ERECT, STRUCTURE IS PHYSICAL STRUCTURE, and INTERRELATED IS INTERWOVEN. These three primitives can be blended in different ways to give rise to compound metaphors that have traditionally been seen as simply "conceptual metaphors." But unlike conceptual metaphors, the combination of these primary metaphors allows for metaphorical concepts without gaps. Combining PERSISTING IS REMAINING ERECT with STRUCTURE IS PHYSICAL STRUCTURE, for example, provides for a compound THEORIES ARE BUILDINGS that nicely motivates the metaphorical inferences that theories need support and can collapse, etc., without any mappings such as that theories need windows. In a similar way, the combination of STRUCTURE IS PHYSICAL STRUCTURE and INTERRELATED IS INTERWOVEN gives rise to a different metaphorical compound for theories, namely, THEORIES ARE FABRICS. This compound metaphor gives rise to the reasonable inferences that theories can unravel or may be woven together, without generating 
less likely entailments such as that theories are colorful in the way that some fabrics have colors. Of course, one might still be able to say that theories are colorful in a deliberate poetic context.

This new work on primary metaphor is a major development in establishing the embodied grounding for metaphor in language and thought. It will be interesting to see how primary metaphors constrain speaking and thinking in linguistic and psycholinguistic accounts of metaphoric language use (see Gibbs, Lima, \& Françozo, 2004).

\section{Skeptical Critique of Conceptual Metaphor Theory (CMT)}

Despite the incredible success, and increasing popularity, of cognitive linguistic work on metaphor, there are numerous criticisms of this research, both from scholars within and outside of linguistics. This section briefly outlines some of these concerns. I present these issues rather informally without citing all the published criticism, because many of these skeptical questions have been voiced to me personally at the many metaphor conferences I attend.

One set of criticisms focus on methodological issues in regard to how cognitive linguists identify metaphors and infer conceptual and primary metaphors from ordinary language. Many critics argue that the linguistic examples cognitive linguists present for analysis are made-up, and may only reflect aspects of the "idealized" speaker-hearer, but not how people ordinarily speak, or write, in naturalistic discourse. A related concern is that all cognitive linguistic analyses are based on individual analysts' intuitions, which are often tied to theories/hypotheses they wish to support. But how does one determine whether any individual word or expression has metaphorical meaning? CMT lacks an explicit identification procedure capable of dealing with real discourse/texts. At the same time, CMT has no explicit method for identifying conceptual metaphors. How does one determine what constitutes adequate systematicity? The cognitive linguistic logic seems circular. Thus, analysts first examine linguistic expressions, enough so to infer the possible presence of underlying metaphorical mappings, but then test this possibility by referring back to language. But independent, nonlinguistic evidence is needed to break open the language- 
to-language circle. Even if one does find systematicity in a set of expressions, how does one determine the actual source-to-target domain mappings, or metaphorical entailments (e.g., what aspects of JOURNEYs get mapped onto the target domain of LIFE in LIFE IS A JOURNEY metaphor?)?

Other criticisms concern how one figures out whether a particular metaphorical mapping is novel or reflects enduring, conventional, metaphorical knowledge. How do different, often similar, conceptual metaphors relate to one another? How do conceptual metaphors fit together in human conceptual systems? How do multiple, contradictory metaphors for a single target domain (e.g., LOVE IS A JOURNEY, LOVE IS MAGIC, LOVE IS A MANUFACTURED OBJECT) cohere. Cognitive linguistics does not yet have a satisfactory theory of underlying conceptual knowledge to deal with issues of contradictory metaphors that constitute complex, abstract concepts.

Beyond the above methodological issues, there are several theoretical questions that many cognitive scientists raise in response to the cognitive linguistic research on metaphor. Perhaps the most important of these is whether the fact that people use metaphor in language necessarily indicates that they are thinking metaphorically. Many critics suggest that analyses of language use and structure may not say anything about human thought. Part of the skepticism here arises from the fact that, again, CMT is based on linguistic analyses that are post-hoc (i.e., based on supposed motivations or partial motivation determined by individual analyst). Scientific theories must have predictive power and must be capable of being empirically falsified. Is CMT really a falsifiable theory? In this regard, psychologists, in particular, suggest that CMT makes unwarranted assumptions about "mental representations," and "language understanding" purely based on linguistic analyses.

Finally, certain linguists, usually those studying pragmatics, claim that CMT is too focused on enduring metaphorical knowledge in language use and ignore the importance of other conceptual and pragmatic information in how people use and interpret metaphorical meaning. CMT puts too much of the emphasis on "metaphor in thought" and says little of how linguistic pragmatic processes are used "on-line" to infer the meanings of metaphors (e.g., relevance theory). 


\section{Responding to the Criticisms}

Some of the above skepticisms represent disciplinary turf wars on the metaphor field of battle. Psychologists, for instance, resent claims about the ubiquity of metaphor in thought without appropriate experimental evidence (but see below). Applied linguists, who typically deal with naturalistic discourse, find the sanitized linguistic examples offered as evidence by cognitive linguists to be far from compelling, and often complain that it is very difficult to conduct systematic analyses of linguistic expressions in quite the way presumed by cognitive linguists. Most generally, scholars from a variety of disciplines are deeply skeptical of people from a different field coming in and announcing that, for instance, that theories of self, the mind, morality, causation, and mathematics are all inherently metaphorical (see Lakoff \& Johnson, 1999).

I am somewhat sympathetic with many of these skeptical reactions. There is a certain arrogance with making claims about mind, body, and culture, entirely on the basis of constructed linguistic evidence But I also believe that linguists, psychologists, and others must explain why it is that people speak in the metaphorical patterns they do across such a wide variety of languages (both spoken and signed). I personally doubt that there is any explanation for the metaphoricity of word meanings, conventional expressions, and novel extensions that does not acknowledge metaphoricity in thought. Simply denying the relevance of cognitive linguistic work to issues of interest to scholars in different fields does not remove the burden from them to explain why language has the patterns it does.

But cognitive linguists should seriously attempt to provide a more comprehensive guide to how they (a) identify metaphors in language, and (b) deduce the presence of systematic conceptual (or primary) metaphors underlying this discourse. Cognitive linguists will, when asked, easily find the metaphors in language and suggest relations to possible conceptual metaphors. But they simply have not said how this is done. Metaphor research would be greatly enhanced if such guidelines could be provided. Cameron (1999, 2003). Steen (1999, this volume) and others have begun taking preliminary steps in trying to provide more concise methods for identifying metaphor in language and thought. Their methods are far more inductive than is the deductive way that cognitive linguists tend to work in identifying conceptual metaphors. Yet the problems these scholars from 
literature and applied linguistics raise about cognitive linguistic methods are right on the mark and merit serious discussion. Psychologists interested in metaphor often seek my advice on what constitutes a metaphor in language and how to infer conceptual metaphors because they have received no guidelines from the cognitive linguistic work. Cognitive linguistics would do well to focus explicitly on providing a set of guidelines, which can be empirically tested and shown to be reliable and reproducible (see Steen, this issue). I make this suggestion in a very positive spirit in the aim of broadening cognitive linguists' influence on the study of metaphor. After all, there are many metaphor scholars who are not cognitive linguists, but who wish to engage in various research based, partly, on the identification of metaphor in language and conceptual metaphors in thought. These people cry out for accessible guidelines that they can reliably employ in doing empirical research that tests specific hypotheses (e.g., psycholinguists), or analyze how metaphors in thought shape speakers/writers' use of metaphoric language (e.g., corpus linguists, applied linguists, literary scholars). Some of the confusion about the definition of metaphor in language and thought arises precisely because there is no public document that suggests how these identifications can be made. The time is ripe for such a document that can serve the broad metaphor community.

A different concern, again, about cognitive linguistic work is that this research is unable to specify what occurs in ordinary, fast, mostly unconscious language use. Of course, cognitive linguists, like scholars from any academic field, are limited in the work they do given the empirical methods they employ in arguing for specific theories of language and thought, for example. Linguists are not psychologists who have an array of techniques for uncovering the fast, unconscious mental processes used in producing and understanding language. Conscious introspections, even those of a trained linguist, are unable to provide the kind of evidence on the psychology of language use, including how thought shapes linguistic interpretation.

But, in fact, contrary to the complaints of many psychologists, there is a growing body of experimental research that presents evidence in support of certain cognitive linguistic claims on metaphor in language and thought. This work generally examines the hypothesis that metaphoric thought motivates real-life, contemporary speakers' use and understanding of why various words and expressions mean what they do. Evaluating this hypothesis requires objective evidence studying people who are not familiar 
with the particular theory at stake. Various psycholinguistic experimental methods have been devised to assess whether (a) people conceptualize of certain topics via metaphor, (b) whether conceptual metaphors assist people in making sense of WHY verbal expressions, particularly idioms and metaphors mean what they do, and (c) whether people access conceptual metaphors during their immediate, online production and comprehension of conventional and novel language. This work includes studies investigating people's mental imagery for conventional metaphors, including idioms and proverbs (Gibbs \& O’Brien, 1990; Gibbs, Strom \& Spivey-Knowlton, 1997), people's context-sensitive judgments about the figurative meanings of idioms in context (Nayak \& Gibbs, 1990), people's immediate processing of idioms (Gibbs, Bogdonovich, Sykes, \& Barr, 1997), people's responses to questions about time (Boroditsky \& Ramscar, 2002; Gentner, Imai, \& Boroditsky, 2002), readers' understanding of metaphorical time expressions (McGlone \& Harding, 1998), and studies looking at the embodied foundation for figurative meanings. Let me briefly discuss this last line of evidence, because this work embraces a research strategy to deal with the problem of circularity of reasoning in cognitive linguistic analyses.

Psychologists have argued that cognitive linguistic work says little about human thought because all of its analyses are language-based. Thus, cognitive linguists start with metaphorical conventional expressions, infer the presence of some conceptual metaphor motivating the meanings of these conventional expressions, which is then tested by seeing if other conventional and novel expressions are also explained by a particular conceptual metaphor. This language-thought-language reasoning processes never really explores the true nonlinguistic, conceptual basis for metaphors. But aspects of my work have attempted to do just this by systematically examining people's nonlinguistic knowledge about source domains, independently of the way these source domains are employed in linguistic expressions. The data from these independent analyses of embodied source domains are used to make predictions about what gets mapped onto different target domains in conceptual and primary metaphors.

For instance, Gibbs (1992) examined people's intuitions of the bodily experiences of containment and several other image schemas. These image schemas serve as the source domains for several important conceptual metaphors (e.g., ANGER IS HEATED FLUID IN A CONTAINER) underlying American speakers' use and understanding of idioms, such as blow your 
stack, flip your lid, and hit the ceiling. Participants imagined their bodies to be container filled with fluid, and then answered questions about the causes and consequences of the fluid exiting the container. These responses provided a rough image-schematic profile of the source domain (e.g., CONTAINMENT) apart from any examination of language (e.g., the cause of the fluid exiting was internal pressure, the escape of the fluid was unintentional, and occurred in a violent manner). Follow-up studies showed that people had precise understanding for idioms, like blow your stack, which could be predicted from the independent analysis of the source domain. Thus, people understand expressions such as blow your stack not to generally mean "get very angry," but something far more specific, namely "one gets angry when feeling intense internal pressure, and exhibits that anger unintentionally in a violent manner." Most generally, the metaphorical mappings underlying idiomatic meanings preserve the cognitive topology of these embodied, image-schematic source domains.

Other experimental studies showed that people's understandings of metaphorical expressions about abstract human desires (e.g., I am starved for his affection, I am hungry for power and fame) are motivated by people's embodied experiences related to feeling hunger, which form the source domain for the primary metaphor DESIRE IS HUNGER (Gibbs, Lima, \& Françozo, 2004; Lima et al., 2001). Participants in both California and Brazil (Campinas) filled out a detailed survey about their experiences of hunger. The survey enabled us to determine what aspects of embodied hunger were most salient and which parts were less prominent. We then showed that people map their salient hunger experiences onto their understanding of the abstract domains of human desires (i.e., love, lust, desire for concrete objects, and desire for abstract events). This is why people rate statements like I craved her affection and I'm completely dizzy for my wife to be more sensible than expressions such as I realized my feet hurt for you.

These various psycholinguistic studies provide independent evidence on the role of embodied metaphorical thought in people use and understandings of conventional language. A critical aim of this work was to avoid the language-thought-language circularity noted in cognitive linguistic work on metaphor in language and thought by independently examining the source domain in conceptual/primary metaphor. This information was then used to make experimental, falsifiable prediction about people's intuitions of linguistic meaning. In this way, the 
psycholinguistic studies provide objective evidence on the role that metaphoric thought plays in conventional language use, but also shows that people are actually accessing conceptual metaphors when interpreting certain kinds of figurative language (Gibbs, 1992), and importantly, may be doing so automatically (Gentner et al., 2002; Gibbs et al., 1997).

My general argument here is that psycholinguistic studies adequately respond to some of the skeptical challenges about cognitive linguistic claims on metaphor. It is important to note that the skeptical claims raised earlier are valid, because cognitive linguistic work by itself is insufficient to conclusively demonstrating metaphors role in thought and realistic language use. But in combination with psycholinguistic evidence, cited and described above, cognitive linguistics has made tremendous strides toward overcoming the restrictive, traditional view of metaphor that still, to some extent, exists among certain scholarly communities.

\section{Future Challenges}

The cognitive linguistic revolution on metaphor continues, although the debates over the role that metaphor plays in language, thought, and culture will surely continue. There are several specific challenges that all metaphor scholars should strive to meet in their respective theoretical and empirical research. Let me briefly outline some of these.

First, metaphor scholars must be explicit in the theoretical goals motivating their work. Scholars too often assume that everyone interested in metaphor is pursuing the same set of questions, or that research findings from one's own field of study should necessarily extend to theoretical concerns of scholars in all disciplines. For instance, cognitive linguists often assume without comment that their ideas on "metaphor understanding" pertain to any theory of metaphor processing, recognition, interpretation, and appreciation. Yet each of these different aspects of metaphoric language use requires different theoretical accounts, and can only be properly described using appropriate research methods from many fields of study. Thus, cognitive linguistic methods are most relevant to demonstrating the ubiquity of metaphor in language, and can suggest conceptual reasons for why this may be so. But cognitive linguistic work can not make definite claims about ordinary speakers' use of metaphorical knowledge in everyday language use and in on-line metaphor production and comprehension. 
Second, in light of the above suggestion, metaphor scholars must recognize the limitations of their own methods. This recognition requires that scholars first firmly establish the identity of their methods, their reliability, and their replicability (e.g., I should be able to apply your method to a set of examples and come up with a similar analysis). This concern may be cognitive linguistics' most significant, immediate challenge, but one that these scholars themselves can address without needing to look for additional evidence from neighboring disciplines (although issues of establishing reliability of methods is a key element in psychological research).

Third, researchers need to know the limits of their respective theories, given the types of metaphoric language they study. Scholars too often assume that accounts of their favorite linguistic examples (e.g., Man is wolf, My surgeon is a butcher, Our relationship has hit a dead-end) will necessarily generalize to a complete theory of metaphor in language and thought. But the diversity of metaphoric language suggests that different metaphorical mechanisms may be needed to explain the motivation and use of different kinds of metaphorical language. Grady (1999), in fact, has nicely described how there are, at least, two motivations for metaphor: resemblance and correlation, each of which underlies different kinds of linguistic statements.

Fourth, as noted above, cognitive linguistic work on metaphor mostly focuses on constructed linguistic examples, and has not examined the interpersonal dynamics that make particular metaphors salient in some discourse context. One observation from conversational analysts is that people mix their metaphors frequently when they talk, and conversational partners even negotiate which metaphors best characterize some emotion, idea, or situation. We need methods for describing these dynamic processes in conversation, and specifically require analytic tools for showing (a) how different linguistic expressions relate to particular conceptual/primary metaphors, (b) how speakers' mixed metaphors reflect different understandings of a topic that may be consistent or inconsistent, and (c) how speakers and addressees work to construct shared metaphoric understandings based on the words they use. Research in sociolinguistics and educational linguistics has presented remarkable findings on the subtle dynamics of real-talk, but too often ignore the constraining presence of metaphorical thought because they have no method available for 
illuminating pervasive schemes in discourse. My hope is that cognitive linguists, and others, will expand their empirical work to explore the sociocultural dynamics of conceptual metaphor.

Finally, little cognitive linguistic work has been devoted to understanding the cultural basis for metaphor in language and thought. Much of the research that does exist examines the extent to which particular conceptual metaphors motivate the existence of specific patterns of conventional expressions in varying languages (Cienki, 1999; Emmanation, 1999; Kovecses, 1999). This work is important in demonstrating the ubiquity of metaphor in thought across culture. Moreover, some of the cognitive linguistic research suggests that the similarities of conceptual metaphors across languages are related to commonalities in embodied experience (Koveceses, 2001; Yu, 1999). But there is still insufficient attention paid to the exact ways that cultural beliefs shape both people's understandings of their embodied experiences and the conceptual metaphors which arise from these experiences. Even if some conceptual metaphor, like LIFE IS A JOURNEY, or some image schema, like CONTAINMENT, seems to underlie metaphoric talk in various languages, this does not necessarily imply that people in different cultural contexts understand journeys or containment in exactly the same way. There is a need for better understanding the cultural grounding not only for the metaphors people use in talking about their experience, but also for the very embodied experiences that often underlie these metaphors.

E-mail: gibbs@cats.ucsc.edu

\section{REFERENCES}

Boroditsky, Lera, and Michael Ramscar. 2002. The roles of body and mind in abstract thought. Psychological Science, 13, 185-189.

Cameron, Lynne. 1999. Defining, knowing, and describing metaphor. In L. Cameron and G. Low (Eds.). Researching and applying metaphor (pp. 105-132). New York: Cambridge University Press. . 2003. Metaphor in educational discourse. New York: Continuum.

CIENKI, Alan. 1999. Metaphor and cultural models as bases and profiles. In R. Gibbs and G. Steen (Eds.), Metaphor in cognitive linguistics (pp. 189-204). Amsterdam: Benjamins. 
Emmanation, Michelle. 1999. Congruence by degree: On the relation between metaphor and cultural models. In R. GibBS and G. Steen (Eds.) Metaphor in cognitive linguistics (pp. 205-218). Amsterdam: Benjamins.

Fauconnier, Gilles, and Mark Turner 2002. The way we think. New York: Basic Books.

FreEman, Donald. 1995. "Catch(ing) the nearest way": Macbeth and cognitive metaphor. Journal Pragmatics, 24, 689-708.

Gentner, Dedre., Mutsumi Imai, and Lera Boroditsky. (2002). As time goes by: Understanding time as spatial metaphor. Language and Cognitive Processes, 17, 537-565.

GibBs, Raymond. 1992. What do idioms really mean? Journal of Memory and Language, 31, 485-506.

. 1994. The poetics of mind: Figurative thought, language, and understanding. New York: Cambridge University Press.

\& Jennifer O'Brien.1990. Idioms and mental imagery: The metaphorical motivation for idiomatic meaning. Cognition, 36, 35-64. , Jody Bogdonovich, Jefferey Sykes, and Dale Barr. 1997. Metaphor in idiom comprehension. Journal of Memory and Language, 37, 141154.

, Paula, Lima, and Edson Françozo. 2004. Metaphor is grounded in embodied experience. Journal of Pragmatics, 36, 1189-1210.

\& Gerard Steen (Eds.) 1999. Metaphor in cognitive linguistics. Amsterdam: Benjamins.

, Lisa Strom, and Michael Spivey-Knowlton. 1997. Conceptual metaphor in mental imagery for proverbs. Journal of Mental Imagery, 21, 83-110.

Grady, Joe.1997. THEORIES ARE BUILDINGS revisited. Cognitive Linguistics, 8, 267-290.

1999. A typology of motivation for conceptual metaphor: Correlation vs. resemblance. In R. GibBs and G. Steen (Eds.), Metaphor in cognitive linguistics (pp. 79-100). Amsterdam: Benjamins.

Johnson, Mark. 1987. The body in mind. Chicago: University of Chicago Press.

Kovecses, Zoltan. 1999. Metaphor: Does it constitute or reflect cultural models. In R. GibBS and G. STEEN (Eds.), Metaphor in cognitive linguistics (pp. 167-188). Amsterdam: Benjamins.

. 2001. Metaphor and emotion. New York: Cambridge University Press. 
LAKOFF, George. 1987. Women, fire, and dangerous things. Chicago: Chicago University Press.

. 1990. The invariance hypothesis: Is abstract reason based on image-schemas Cognitive Linguistics, 1, 39-74.

\& Mark Johnson.1980. Metaphors we live by. Chicago: Chicago University Press.

\& Mark Johnson. 1999. Philosophy in the flesh. New York: Basic Books.

\& Mark Turner. 1989. More than cool reason: A field guide to poetic metaphor. Chicago: Chicago Press.

Lima, Paula Lenz Costa, Raymond Gibbs, and Edson Françozo. 2001. Emergência e natureza da metáfora primaria : Desejar é ter Fome. Cadernos de Estudos Linguisticos, 40, 107-140.

McGlone, Mathew, and Julia Harding. 1998. Back (or forward) to the future: The role of Perspective in temporal language comprehension. Journal of Experimental Psychology: Learning, Memory, and Cognition, 24, 1211-1223.

NAYAK, Nandini and Raymond GibBs. 1990. Conceptual knowledge in the interpretation of idioms. Journal of Experimental Psychology: General, 119, 315-330.

Steen, Gerard. 1999. From linguistic to conceptual metaphor in five steps. In R. GibBs and G. Steen (Eds.), Metaphor in cognitive linguistics (pp. 57-78). Amsterdam: Benjamins.

. This volume. Metaphor in applied linguistics: Four approaches to metaphor in language and thought.

SwEETSER, Eve.1990. From etymology to pragmatics: The mind-body metaphor in semantic structure and semantic change. Cambridge: Cambridge University Press

TAUB, Sarah. 2001. Language from the body. New York: Cambridge University Press.

Wilcox, Phyllis. 2001. Metaphor in American Sign Language. Washington, DC: Gallaudet.

Yu, Ning. 1999. The contemporary theory of metaphor. Amsterdam: Benjamins. 